\title{
Una lectura del Quijote. Avellaneda y el Conde Peranzules
}

\author{
BEATRIZ MARISCAL HAY*
}

Cuando Miguel de Cervantes termina de escribir El ingenioso hidalgo don Quijote de la Mancha, declara que sus lectores son libres de decir lo que quieran sobre el libro, ya que al no ser ni parientes, ni amigos de su "hijastro", estaban exentos de todo respecto y obligación ${ }^{1}$.

Con su libro, Cervantes pretendía llegar al mayor número de lectores posible: tanto los melancólicos como los risueños, los simples y los discretos, al igual que los graves y prudentes podrían encontrar en la historia de su "casto enamorado y valiente caballero" diversión y entretenimiento, lo que esperaba le daría fama y beneficios económicos.

Entre la gran variedad de lectores de su obra, Cervantes sabía que seguramente habría algunos que no tendrían la capacidad de captar correctamente su sentido. Lo que no esperaba es que uno de ellos se apropiara de su criatura y, en una lectura desatinada de su obra, pretendiera continuarla, apropiándose de paso de los beneficios que sólo a él correspondían: una cosa era decir de ella lo que quisieran y otra hacer con ella lo que quisieran.

Este breve trabajo está dedicado a un aspecto de la desatinada lectura que dio lugar a la pretendida continuación de la genial "invectiva contra los libros de caballerías" de Miguel de Cervantes, a la utilización que hace Avellaneda de romances relacionados con el cerco de Zamora para componer su espuria continuación de El ingenioso hidalgo don Quijote de la Mancha, y su posible influencia en la Segunda Parte del Quijote cervantino ${ }^{2}$.

* El Colegio de México.

1. Todas las citas del Quijote de Cervantes proceden de la edición del Instituto Cervantes, dirigida por Francisco Rico, Barcelona, Galaxia de Gutemberg/ Círculo de Lectores, 2004.

2. Cervantes utiliza bastantes más romances en la segunda parte de su obra que en la primera, lo que en mi opinión se relaciona con su lectura de la obra de su rival. 
Es tan conocida como debatida la teoría de Menéndez Pidal de que el Entremés de los romances habría sido un primer estímulo de Cervantes para la composición de su novela. En su opinión, Cervantes habría descubierto la gracia que tenía un loco lector de romances y eso lo habría llevado a crear su personaje, un loco lector de novelas de caballería, obras cuya popularidad era motivo de preocupación para muchos de sus contemporáneos ${ }^{3}$. El hecho de que Cervantes adjudique finalmente a las novelas de caballería y no al Romancero la locura de don Quijote se debería, según Menéndez Pidal, a su admiración por el Romancero 4 .

Ya sea que Menéndez Pidal esté en lo cierto en cuanto a esa fuente de Cervantes, o que, por el contrario, el autor del Entremés se haya inspirado en el Quijote de Cervantes, como sostienen críticos como Cotarelo y Mori y Rodolofo Schevill, entre otros, lo innegable es que Cervantes utiliza el Romancero como inspiración de algunas hazañas de don Quijote y como parte de su lenguaje y, en otra medida, del de Sancho y de otros personajes que responden a ambos con referencias o versos de romance ${ }^{5}$. Estas citas y referencias son a menudo guiños irónicos con los que Cervantes se comunicaba con sus lectores, quienes esperaba reconocerían los romances que utilizaba y comprenderían el valor paradigmático de esos versos o fragmentos de romances ${ }^{6}$.

3. MenÉndez PIDAL establece 1591 como fecha de publicación del Entremés, ya que la Flor de Romances, donde aparecen los romances citados en el Entremés se publicó en 1591-1597. Véase MENÉNDEZ PIDAL, Ramón, De Cervantes y Lope de Vega, Madrid, Espasa Calpe, 1958 (1. a ed. 1940). Por su parte, ANTONIO PÉREZ LASHERAS considera que el Entremés debió escribirse poco después de febrero de 1592, lo que confirmaría la fecha propuesta por Stagg para el comienzo de la escritura del Quijote. Véase: PÉrez LASHERAS, Antonio, "El Entremés de los romances y los romances del Entremés" en La recepción del texto literario. (Coloquio Casa de Velásquez-Departamento de Filología Española de la Universidad de Zaragoza, Jaca, abril de 1986), Jean-Pierre Etienvre y Leonardo Romero (coords.), Zaragoza, Universidad de Zaragoza, 1988, pp. 61-76. La inclusión en el Entremés de los romances del romance de Góngora: Ensíllenme el asno sucio, una evidente parodia del romance de Lope: Ensíllenme el potro rucio, en opinión de José LóPEZ NAvío lo convierte en una sátira del propio Lope. Esta sátira personal contra Lope sería también parte del Quijote. Véase: LóPEZ NAvío, José, "El Entremés de los romances, sátira contra Lope de Vega, fuente de inspiración de los primeros capítulos del Quijote", Anales Cervantinos, VIII (1959-1960) pp. 151-239. Sobre la relación entre el Quijote y el Entremés véase también: BARAs EscolÁ, Alfredo, "El Entremés de los romances y la novela corta del Quijote, Actas del III Coloquio de la Asociación Internacional de Cervantistas, Barcelona, Anthropos/ Madrid, Dirección General de Relaciones Culturales y Científicas, 1993, pp. 331-335.

4. Fernando LÁZARo CARRETER considera que no tiene sentido exigir una distinción precisa entre lo caballeresco y lo romanceril en el Quijote, ya que en tiempos de Cervantes ambos géneros se confundían en la opinión general. En los Romanceros impresos, observa, los hechos fabulosos de la caballería se mezclaban con los de los paladines épicos. Si Cervantes se hubiera "arrepentido" de haber atribuido inicialmente al Romancero "la locura del nobilísimo caballero de la Mancha", como pensaba Menéndez Pidal, en la opinión de Lázaro Carreter, hubiera reelaborado los capítulos en que imitaba al Entremés. Véase: LÁZARo CARreter, Fernando, "Estudio Preliminar" de la edición del Quijote arriba citada, pp. xxvi-xxix.

5. Un ejemplo es el ventero, quien ante la declaración de don Quijote de que no necesita lecho para dormir, en la que incluye la cita del romance de Mis arreos son las armas: "Para mi, señor castellano, cualquiera cosa basta, porque mis arreos son las armas, mi descanso el pelear, etc.", en su respuesta hace patente su propio conocimiento del romance: "-Según eso, las camas de vuestra merced serán duras peñas, y su dormir, siempre velar y siendo así, bien se puede apear...” (Quijote I, 2).

6. Los estudios de Giuseppe Di Stefano y GiUlianA Piacentini sobre la difusión impresa de ro- 
Dada esta familiaridad de los lectores con el Romancero, éste termina siendo un elemento más de esa verosimilitud cultural que informa su obra.

A su imitador Avellaneda no había de pasarle de largo el uso que hace Cervantes del Romancero en su obra, por lo que lo hizo parte de su espuria continuación, pero, al igual que en casi todos los aspectos en que pretende copiar el modelo cervantino, exagera la nota y utiliza el Romancero a menudo de manera desatinada, por lo que no logró, tampoco en esto, igualar al maestro ${ }^{7}$.

Esa lectura incorrecta del modelo a imitar, en mi opinión, no sólo hace patente la distancia que hay entre el arte de ambos escritores, sino que nos proporciona pistas de gran interés sobre la esquiva personalidad del autor de la imitación.

Centro mis observaciones en el capítulo VI del Quijote de Avellaneda ${ }^{8}$, un capítulo que comprende una de las aventuras que el autor seguramente consideró "apegadas" al modelo de aventuras Cervantinas: el ataque de don Quijote a un hombre que cuida un campo de melones, a quien "confunde" con Orlando el Furioso, encantado por un moro y puesto a guardar la entrada de un castillo; todo lo cual estaba dicho, según nos informa el propio personaje, en un libro "auténtico y verdadero" llamado Espejo de caballerías 9 .

Después de encarecer el valor legendario de Roldán el Furioso, el falso Quijote se propone enfrentarse al melonero/Roldán, a fin de hacer suyas "las glorias, victorias, buenos sucesos, fazañas, vencimientos, muertes de gigantes, desquijaramientos de leones y rompimientos de ejércitos", con lo que sería temido y aun llamado a corte por el rey de España. Sancho cumple con su función desmitificadora y le hace ver que se trata simplemente de un hombre armado de un lanzón que cuida un melonar. Pero Don Quijote le asegura que no puede dejar pasar semejante oportunidad de ganar honra y fama, ya que ese fue el motivo para salir de su casa.

El resultado es previsible, don Quijote avanza sobre su triste cabalgadura y, cuando llega junto al melonero, pone la lanza en tierra e increpa a "Orlan-

mances en los siglos xvi y xvii muestran que los romances de tema épico e histórico no tenían la preferencia del público, ni de los recolectores, impresores o autores de ensaladas, quienes se interesaban más por los romances novelescos, mientras que los refundidores y editores utilizaban preferentemente los romances de tema épico-histórico. Véase: Di Stefano, Giuseppe, La difusión impresa del romancero antiguo en el siglo XVI, RDTP, t. XXXIII (1977); PIACENTINI, Giuliana, Ensayo de una bibliografía analítica del Romancero antiguo.(Siglos XV y XVI), fascículo I: Los Pliegos Sueltos, fascículo II: Cancioneros y Romanceros, Pisa, Giardini Editori, 1981 y 1986 y "Romances en ensaladas y géneros afines", El Crotalón, 1 (1984), pp. 1135-1173.

7. MenÉndez Pidal, Ramón, op. cit., era de la opinión que Avellaneda abusaba de los desvaríos sobre romances en su obra.

8. Todas las citas del Segundo tomo del ingenioso hidalgo don Quijote de la Mancha, que contiene su tercera salida y es la quinta parte de sus aventuras, de ALONSO FERNÁNDEZ DE AvELLANEDA, provienen de la edición de Luis Gómez Canseco, Madrid, Biblioteca Nueva, 2000.

9. Gómez CANSECo señala en su edición del Quijote de Avellaneda arriba citada que el Espejo de caballería, publicado en 1533 en Sevilla, por Juan Cromberger, era una adaptación libre y parcial del Orlando Innamorato de MATteo Boiardo, iniciada por Pedro LóPez de SANTA CATAlina, con una tercera parte compuesta por PEDRO DE REINOSA. Los tres libros se publicaron en 1586. El libro es incluido por Cervantes en la biblioteca de don Quijote que el cura expurga. Véase la nota 7 del capítulo VI. 
do": no le valdrán ni encantamientos, ni los ejércitos de Carlomagno; el encuentro se hará uno a uno. Para igualar a su enemigo que está en tierra, se baja de Rocinante y animado por Sancho, quien le comunica que ha asegurado el apoyo de San Antón y las benditas ánimas, pues ha prometido decir una misa $^{10}$, prosigue contra el melonero quien, al ver que no se detiene, se deshace del lanzón y le arroja piedras con una honda, con las que alcanza primero el brazo izquierdo y después el medio del pecho de don Quijote que cae aturdido en tierra.

Cuando Sancho acude a preguntar a su amo si está malherido, éste insiste en que a pesar de haber sido derribado por "una gran peña" y de haber sido herido en el brazo por "una terrible maza", ha sido una victoria de su parte ya que el enemigo ha huido. Sancho aclara que no hubo ni peñas ni mazas, se trató de dos guijarros arrojados por una honda, que bien hubieran podido darle en la cabeza, por lo que debe agradecer estar aun con vida a: "un romance que yo recé del conde Peranzules, que es cosa muy probada para el dolor de ijada"11.

Es bien sabido que durante el Siglo de Oro la práctica de verter "a lo divino" temas profanos gozó de gran popularidad. Recordemos que el mismo San Juan de la Cruz se inspira en la poesía de Boscán "trasladado a materias cristianas y religiosas"; esos "locos devaneos del amor convertidos en materia religiosa", como los llama Dámaso Alonso ${ }^{12}$. Pero no eran sólo los lectores cultos los que se entretenían con la poesía divinizada, sino que, con el "vulgo" en mente, se hicieron contrafacturas a lo divino de romances tradicionales y nuevos, así como de otros géneros de poesía popular, que eran difundidas por medio de pliegos sueltos y cancionerillos de bolsillo.

Son muy numerosos los ejemplos de romances de tema religioso, como los publicados en el Romancero espiritual de Josef de Valdivielso (Toledo, 1612) o los compuestos por Juan López de Úbeda, muchos de ellos contrafacturas a lo divino de romances de tema épico - histórico, publicados en su Cancionero general de la doctrina cristiana (1579) y en su Vergel de flores divinas (1582), entre los que aparece el romance de las Quejas de la Magdalena, aun presente en la tradición oral moderna, basado en el romance de las Quejas de doña Urraca, que comienza "Morir vos queredes, padre,/ San Miguel vos haya el alma;// mandaste las vuestras tierras/ a quien se vos antojara,// a don Sancho a Castilla,/ Castilla la bien nombrada,// a don Alonso a León,/ y a don

10. En su libro Cervantes y Avellaneda. Estudio de una imitación, México, el Colegio de México, 1951, STEPHEN GILMAn señala que la imitación de Avellaneda no es inofensiva, ya que intensifica las posibilidades de instrucción contrarreformista del relato sobre las peripecias de don Quijote y Sancho.

11. La personalidad del Sancho de Avellaneda es, como sabemos, invariable de principio a fin y está marcada por su ignorancia, su gula y su carácter pusilánime y supersticioso. En el siglo XVII, las clases populares eran muy aficionadas a rezos con fines amorosos y curativos. La Inquisición no veía con buenos ojos esas creencias y en numerosos juicios por hechicería incluía ensalmos como prueba de culpa.

12. Alonso, Dámaso, La poesía de San Juan de la Cruz, Madrid, CSIC, 1942, pp. 47-100. 
García a Vizcaya.// A mí, porque soy mujer,/ dejaisme desheredada"13; mencionado lo mismo en el Quijote de Cervantes que en el de Avellaneda, quienes recuerdan además la amenaza de la infanta de prostituirse en razón del desamparo en que la deja su padre, y que en la versión a lo divino comienza: "Moriros quereys, mi Dios,/ vuestro padre el alma os aya,// mandastes las vuestras tierras/ a quien bien os agradara:// al ladrón distes la gloria,/ ésta fue la primer manda// y heredero le hezistes/ de vuestra gloria sagrada,// ...// Y a mi, porque soy mujer,/ no me encomendastes nada" 14 .

Es esta práctica literaria la que habría convertido el romance sobre el conde Peranzules que menciona Sancho en una oración que pudiera recitarse a modo de ensalmo, para curar el dolor de ijada.

Pero más allá de incluir en su obra una utilización del Romancero tradicional que no está presente en la obra de Cervantes, el rezo de romances para curar enfermedades, Avellaneda trae a la palestra a un personaje, el conde Peranzules, con vida tanto romancística como histórica, sobre el que vale la pena reflexionar.

En primer lugar, quiero insistir que, en mi opinión, la mención del conde Peranzules, Pedro Anzures, por parte de Avellaneda, no es casual, ya que en ese mismo capítulo don Quijote recita el comienzo del romance del rey Don Sancho: "Rey Don Sancho, rey Don Sancho,/ no digas que no te aviso// que del cerco de Zamora/ un traidor había salido//15. Y, asumiendo que Sancho no conoce el romance, le aclara que el traidor sobre el que es avisado el rey don Sancho es Bellido de Olfos, hijo de Olfos Bellido, quien, cuando él, al igual que el rey don Sancho, se bajó del caballo para "proveerme detrás de unas matas", le tiró un venablo a traición y lo dejó "como me ves"16.

Por ello, conviene que Sancho se suba "en un poderoso caballo, llamándote don Diego Ordóñez de Lara, y que vayas a Zamora, y en llegando junto a la muralla, verás entre dos almenas al buen viejo Arias Gonzalo ante quien re-

13. Primavera núm.36. Durán núm. 736. Las citas de los romances derivados del *Cantar del rey Fernando proceden de Wolf, Fernando J. y Hofman, Conrado, Primavera y flor de romances de. Segunda edición corregida y adicionada por MenÉndeZ y PELAYo, Marcelino, Madrid, 1899, en Antología de poetas líricos castellanos, VIII, Madrid, CSIC, 1945, y de DURÁN, Agustín, Romancero general o Colección de romances castellanos anteriores al siglo XVIII. (Parte 2. ${ }^{\mathrm{a}}$ De los Romances Viejos, III), Madrid, M. Rivadeneyra, 1849-1851.

14. Citado por Catalán, Diego, "El romancero espiritual en la tradición oral (1985)", Arte poética del romancero oral. Parte 1. ${ }^{a}$ Los textos abiertos de creación colectiva, Madrid, Siglo XXI, 1997, pp. 271-72.

15. Primavera núm. 44. Este romance también fue contrahecho a lo divino, entre otros, por LOPE DE VEGA (El Príncipe de la paz y La Margarita preciosa) y por el novohispano FERnÁN GoNZÁLEZ DE ESLAVA: "Guarte, guarte, pecador/ no digas que no te aviso,// que de la cueva infernal/ tres traydores han salido:" Véase FrEnK, Margit, Fernán González de Eslava. Villancicos, romances, ensaladas y otras canciones devotas. "Biblioteca Novohispana”, I, México, El Colegio de México, 1989, pp. 332 y 412-413.

16. El romance dice: "Desque el rey lo ha rodeado/ saliérase cabe el río,/ do se hubo de apear/ por necesidad que ha habido./ Encomendóle un venablo/ a ese malo de Vellido:/ dorado era y pequeño,/ que el rey lo traía consigo./ Arrojóselo el traidor,/ malamente lo ha herido;/ pasóle por las espaldas,/ con la tierra lo ha cosido." 
tarás a toda la ciudad, torres, cimientos, almenas, hombres, niños y mujeres, el pan que comen y el agua que beben, con todos los demás retos con que el hijo de don Bermudo retó a dicha ciudad, y matarás a los hijos de Arias Gonzalo, Pedro Arias y los demás". Una referencia directa, como sabemos, a otro de los romances del ciclo del cerco de Zamora, que refiere el reto que hace Diego Ordóñez a los zamoranos ${ }^{17}$.

Más allá de lo grotesco que resulta este exhorto a Sancho, no podemos perder de vista que el conde Peranzules, mencionado por Sancho, toma parte en las acciones que refieren los romances sobre el cerco de Zamora, sobre la muerte del rey don Sancho y sobre sus consecuencias históricas, en las que habría de jugar un papel importante el Cid Campeador.

El conde Peranzules aparece en varios romances de ese ciclo. En primer lugar, como consejero del rey Alfonso, en el romance que comienza: "Doña Urraca, aquesa infanta,/ mensajeros ha enviado// que vayan con las sus cartas/ a don Alfonso su hermano", en el que Peranzules, calificado como "un caballero afamado", interfiere la llegada de los mensajeros de Urraca, les corta la cabeza y aconseja a su rey que salga de Toledo en secreto. A pesar de que don Alfonso decide comunicarle al rey Alimaimon lo que ha sucedido, el consejo de Peranzules, de proceder con sigilo, es acatado por el rey Alfonso, y ambos parten rumbo a Zamora a la media noche. Para no ser descubiertos se descuelgan "con sogas y maromas" por el muro y cabalgan al amparo de la oscuridad $^{18}$.

En otro de los romances sobre este tema: "En Toledo estaba Alfonso,/ que non cuidaba reinar", el consejo del conde Peranzules es que, para no dejar huella, deben herrar al revés los caballos ${ }^{19}$.

Pedro Anzures aparece también en un romance del Romancero historiado de Lucas Rodríguez: "Después que sobre Zamora/ murió el noble rey don Sancho", que trata sobre la ira del rey Alfonso por el rigor con el que el Cid le tomó la jura en Santa Gadea. En él, como “ayo" del rey Alfonso, el conde Peranzules le aconseja que haga el juramento: "Luego habló Pero Anzures,/ un ayo que lo ha criado:// -Poné la mano señor, / y jurá pues, que estais salvo, / que nunca fuiste traidor,/ ni sabeis nada en tal caso"20.

En ninguno de esos romances el conde Anzures es protagonista con la importancia necesaria para llamarlo "romance de Peranzules", bueno para el dolor de ijada.

Veamos dos posibilidades más. Una de ellas es el romance atribuido a Lorenzo de Sepúlveda: Lealtad de Pedro Ansúrez, que comienza: "Muerto es el

17. El romance dice: "-Yo riepto a los de Zamora,/ por traidores conoscidos:/ porque fueron en la muerte/ del rey don Sancho mi primo,/ y acogieron en la villa/ al que esta traición hizo./ Por eso fueron traidores,/ en consejo, fecho y dicho:/ por eso riepto a los viejos,/ por eso riepto a los niños,/ y a los que están por nascer,/ hasta los recién nascidos;/ riepto al pan, riepto las carnes;/ riepto las aguas y el vino,/ desde las hojas del monte/ hasta las piedras del río.” Primavera núm. 47a.

18. DurÁn, núm. 807.

19. Romance del rey don Alfonso, Primavera núm. 51; DuRÁn, núm. 808.

20. DuRÁn, núm. 814. 
rey Alfonso,/ el que a Toledo ganara,// y por ser el rey tan bueno/ su muerte fue muy llorada", que trata de la exigencia de la infanta Urraca de que le entreguen las tierras que heredara de su padre ${ }^{21}$. El conde Pedro Ansúrez le entrega las tierras que le habían concedido a él, puesto que se las ha pedido "su natural señora".

Es interesante señalar que en 1912 uno de los corresponsales de Menéndez Pidal le remitió un fragmento de este romance, recogido de la tradición oral en Colombia, cuyo informante parece haberlo aprendido del Romancero General de Durán ${ }^{22}$. La ambigüedad de este romance que por un lado encarece la lealtad del conde Pero Anzures a doña Urraca, hija de Alfonso VI, y por otro señala que su acción constituye una traición al rey de Aragón: "Y díjole: -Rey Alfonso,/ aquí fue la mi llegada/ a ponerme en vuestra mano,/ como aquel que mal obraba", tampoco parece prestarse a su "santificación".

Un romance más sobre Peranzules es el conocido con el nombre de "Cabalgada de Peranzules" que aparece en los romanceros del siglo XVI como "Romance de la Infanta Sevilla y Peranzules"23. El romance, del que se han recogido hasta una docena de versiones de la tradición oral moderna, refiere cómo la infanta Sevilla otea el horizonte desde una alta torre y ve venir a lo lejos un caballero con una cadena de presos que descubre está formada por su padre y hermanos mayores. Lo persigue otro caballero que reclama los cautivos. Se da un duro combate entre ambos y, finalmente, el caballero Peranzules vence al moro. En las versiones modernas desaparece la infanta y quien otea el horizonte es el rey don Fernando o simplemente "un caballero"24.

El origen de este romance es dudoso, Samuel Armistead propone la chanson de geste de Guillaume d'Orange como fuente del mismo y no una fuente épica nacional ${ }^{25}$. Independientemente de su origen, lo que no parece muy probable es que, como es el caso de los otros romances que tratan de Peranzules, se hubiera convertido en ensalmo.

Pasemos al Peranzules histórico. El conde Pedro Ansúrez fue, efectivamente, consejero del rey Alfonso y lo que es más importante, Conde de Carrión, Saldaña, Liébana y Zamora, hermano de Gonzalo Ansúrez, padre de los yernos del Cid y uno de sus más poderosos enemigos. Según la crónica de Fray Juan Gil de Zamora, De praeconiis Hispaniae (1278 y 1282), basada en

21. DURÁn, núm. 917.

22. Consúltese CATAlán, Diego, Catálogo general del Romancero pan- hispánico. Teoría General. CGR 1.A. con la colaboración de CID, J. Antonio, MARISCAL, Beatriz, SAlazAR, Flor, VALENCIANo, Ana y Robertson, Sandra. Madrid, Seminario Menéndez Pidal, 1984, p. 31.

23. Cfr. la Rosa gentil. Tercera parte de Romances de Joan Timoneda que tratan de historias Romanas y Troyanas (1573). Para la descripción de este romance véase el volumen 2 del arriba mencionado catálogo: CGR 2, Madrid, Seminario Menéndez Pidal, 1982, pp. 179-183.

24. Véase Armistead, Samuel G., con la colab. de Margaretten, Selma, Montero, Paloma, y Valenciano, Ana, El Romancero judeo-español en el Archivo Menéndez Pidal. (Catálogo-índice de romances y canciones), 3 vols., Madrid, Cátedra-Seminario Menéndez Pidal, 1978. Vol. I, pp. 284-286.

25. Armistead, Samuel G., "La cabalgada de Peranzules: A Posible Epic Congener", en Historicist Essays on Hispano-Medieval Narrative. In Memory of Roger M. Walker. Modern Humanities Research Association, 2005, pp. 41-52. 
la Historia gótica (1243) del arzobispo Rodrigo Ximenez de Rada, pero con una visión localista que busca engrandecer la bondad de los zamoranos y leoneses y la perfidia de los castellanos y el tirano rey don Sancho, Arias Gonzalo lleva personalmente la noticia de la muerte del rey don Sancho a Toledo. Para escapar, don Alfonso acepta que Pedro Ansúrez quede como rehén en Toledo y haga homenaje al rey moro. Alfonso llega a Zamora, su hermana lo recibe y le propone matrimonio incestuoso y que la reconozca como reina. Alfonso se niega y la princesa lo mete en prisión. Finalmente llega Pedro Ansúrez y negocia con Arias Gonzalo que doña Urraca entregue Zamora a su hermano y que a cambio el rey entregue su cuerpo y reino a la infanta, pacto que ambos juran sobre los evangelios. En cumplimiento del pacto, Arias Gonzalo, con Llaín Cides entrega Zamora a Alfonso. Los hermanos celebran sus bodas y hacen a Pedro Ansúrez señor de Zamora ${ }^{26}$.

Junto con Urraca, Pedro Ansúrez había actuado igualmente como consejero de Alfonso para que metiera en prisión a su hermano don García, quien finalmente murió encarcelado en el Castillo de Luna ${ }^{27}$.

El conde Pedro Ansúrez es, por tanto, un importante personaje del bando Alfonsí y uno de los más temibles enemigos del Cid, si bien, paradójicamente, actúa como fiador, junto con García Ordóñez, otro de sus enemigos poderosos, de la carta de arras del Cid en su boda con Jimena Díaz ${ }^{28}$.

Aurora Egido proponía que "no fue el azar sino la historia la que encaminó a don Quijote a Zaragoza, el lugar más propicio de España para afirmar su autenticidad en los albores del siglo XVII", ya que en esa ciudad la Cofradía de San Jorge continuaba llevando a cabo el tipo de fiestas caballerescas en las que aspiraba participar nuestro caballero andante, pero, como sabemos, al aparecer la obra de Avellaneda, renuncia a ir a Zaragoza que se convierte en símbolo de la usurpación ${ }^{29}$.

Avellaneda tampoco escoge al azar al conde Peranzules como personaje de su relato y como modelo de heroicidad; hace referencia a él en varias ocasiones. En el capítulo 2, cuando don Álvaro, riéndose, celebra la carta que envió don Quijote a Dulcinea, equiparándola con "la que en su tiempo pudo escribir el rey don Sancho de León a la noble doña Jimena Gómez, al tiempo que, por estar ausente della el Cid, la consolaba", si bien su estilo estaba "fuera de tiempo", don Quijote responde, que así la escribe porque "ya que imito a los antiguos en la fortaleza, como son al conde Fernán González, Peranzules, Bernardo y al Cid, los quiero también imitar en las palabras".

Peranzules reaparece, como ya vimos, en el capítulo 6, cuando el autor convierte un romance de Peranzules en ensalmo, y aparece asimismo en el ca-

26. Consúltese: CATALÁn, Diego, La épica española. Nueva documentación y nueva evaluación, Madrid, Fundación Ramón Menéndez Pidal, 2001, pp. 91-97.

27. LÉvi-Provençal, E. y MenÉndez Pidal, Ramón, “Alfonso VI y su hermana Urraca”, $A l-A n$ dalus, XIII, 1948, pp. 157-166.

28. MenÉndeZ Pidal, Ramón, La España del Cid, 2 vols. (4. a ed.), Madrid, Espasa Calpe, 1947.

29. EGIDo, Aurora, "La Cofradía de San Jorge y el destino de don Quijote" en Cervantes y las puertas del sueño. Barcelona, PPV, 1994. 
pítulo 24, cuando nuevamente se hace mención del lenguaje de don Quijote y se señala correspondería "a los cándidos siglos del conde Fernán González, Peranzules, Cid Ruiz Díaz y de los demás antiguos".

A la hora de escoger entre héroes históricos y héroes literarios, el Quijote de Cervantes toma partido por los literarios y, de manera especial, por los que procedían de las novelas de caballería. Si bien el Cid Ruy Díaz en su opinión había sido gran caballero, no aventajaba al Caballero de la Ardiente Espada, capaz de dar cuenta de gigantes. Ello no obstante, en su panteón de héroes cabían bien Bernardo del Carpio y Reinaldos de Montalbán, héroes del romancero carolingio, ya que su heroicidad era acorde con la propugnada por los libros de caballería. (Quijote I, 1).

Avellaneda aprovecha todos los héroes mencionados por Cervantes, pero agrega a un personaje marcado por su pertenencia al bando contrario a los castellanos: el conde Peranzules, poderoso enemigo del Cid, tío de sus yernos traidores, además de ayo y consejero de Alfonso, rey que envió al Cid al destierro.

Con la publicación de la obra de Avellaneda como acicate, Cervantes afina su ingenio creador y aprovecha su propia continuación para denostar y desenmascarar a su plagiario, evidenciando sus incongruencias y excesos ${ }^{30}$.

En su segunda parte del Quijote, Cervantes utiliza muchos más romances de los que había incluido en la primera parte, entre ellos, el relativo al reto de Diego Ordóñez a los zamoranos que, como hemos visto, había utilizado Avellaneda. Cervantes, al igual que su rival, también pone el romance del reto a los zamoranos en boca de don Quijote, quien lo menciona a propósito del ridículo episodio de los rebuznos. Después de señalar los excesos del reto de Diego Ordóñez al pueblo zamorano, comenta: "aunque bien es verdad que el señor don Diego anduvo algo demasiado, y aun pasó muy delante de los límites del reto, porque no tenía para que retar a los muertos, a las aguas, ni a los panes, ni a los que estaban por nacer, ni a las otras menudencias que allí se declaran; pero vaya, pues cuando la cólera sale de madre, no tiene la lengua padre, ayo ni freno que la corrija". (Quijote II, 27)

No voy a tratar aquí de la posible influencia que tuvo en la segunda parte del Quijote cervantino la utilización por parte de Avellaneda de romances como el que venimos comentando; me limito a señalar que Cervantes hace este uso irónico del romance del reto a los zamoranos en el capítulo 27 , mucho antes del tan comentado capítulo 59, que ha sido considerado por algunos críticos como punto de partida de la reacción de Cervantes al libro de Avellaneda, y que esta mención irónica del romance por parte de Cervantes es, a mi ver, parte de su estrategia para evidenciar la inferioridad del Quijote espurio.

Avellaneda no supo leer correctamente el libro de Cervantes, su iracundo y falso don Quijote carecía, en palabras de Cervantes, "de todo razonable dis-

30. Puesto que Cervantes declara en el "Prólogo al lector" que su rival "... no osa parecer a campo abierto y el cielo claro, encubriendo su nombre, fingiendo su patria,", es muy probable que supiera de quién se trataba, si bien no nos lo comunica. Vaya esta modesta propuesta sobre lo que pueda representar la afinidad política del plagiario a la discusión sobre su identidad. 
curso"; al tiempo que los héroes que invoca el plagiario tienen más que ver con sus propias afinidades nacionales que con los héroes del Romancero que aparecían en su modelo.

Para apropiarse de la genial invención cervantina, no bastó con que Avellaneda invocara al conde Peranzules, ya que éste no pudo valerle como ayo ni freno que lo corrigiera.

De ahí que el propio Cervantes se encargara de ridiculizar a su imitador mostrándolo como un mal lector de la obra que había pretendido continuar.

\title{
Resumen
}

Este trabajo está dedicado a un aspecto de la desatinada lectura de Avelladena que dio lugar a la pretendida continuación de la "genial invectiva contra los libros de caballería" de Miguel de Cervantes. Se centra en la utilización que hace Avellaneda de romances relacionados con el cerco de Zamora para componer su espuria continuación de El Ingenioso Hidalgo don Quijote de la Mancha y su posible influencia en la segunda parte del Quijote cervantino.

Palabras clave: Quijote / Peranzules / Romancero / Avellaneda

\begin{abstract}
This essay looks into Avellaneda's equivocal reading of Cervantes' masterful "invention against books of chivalry", that resulted in his spurious continuation of El Ingenioso Hidalgo don Quijote de la Mancha. It focuses on the meaning of Avellaneda's use of romances dealing with the siege of Zamora, and its possible influence on Cervantes' own second part of the Quijote.
\end{abstract}

Key words: Quijote / Peranzules / Romancero / Avellaneda 